\title{
Germinating Spore Exudates from Arbuscular Mycorrhizal Fungi: Molecular and Developmental Responses in Plants and Their Regulation by Ethylene
}

\author{
Arijit Mukherjee and Jean-Michel Ané \\ DOE Great Lakes Bioenergy Research Center, Department of Agronomy, University of Wisconsin, Madison, WI 53706, U.S.A.
}

Submitted 30 June 2010. Accepted 27 October 2010.

\begin{abstract}
Arbuscular mycorrhizal (AM) fungi stimulate root development and induce expression of mycorrhization-specific genes in both eudicots and monocots. Diffusible factors released by AM fungi have been shown to elicit similar responses in Medicago truncatula. Colonization of roots by AM fungi is inhibited by ethylene. We compared the effects of germinating spore exudates (GSE) from Glomus intraradices in monocots and in eudicots, their genetic control, and their regulation by ethylene. GSE modify root architecture and induce symbiotic gene expression in both monocots and eudicots. The genetic regulation of root architecture and gene expression was analyzed using $M$. truncatula and rice symbiotic mutants. These responses are dependent on the common symbiotic pathway as well as another uncharacterized pathway. Significant differences between monocots and eudicots were observed in the genetic control of plant responses to GSE. However, ethylene inhibits GSE-induced symbiotic gene expression and root development in both groups. Our results indicate that GSE signaling shares similarities and differences in monocots versus eudicots, that only a subset of AM signaling pathways has been co-opted in legumes for the establishment of root nodulation with rhizobia, and that regulation of these pathways by ethylene is a feature conserved across higher land plants.
\end{abstract}

In most natural and agronomic ecosystems, the availability of water and nutrients such as nitrogen, phosphate, and potassium are major limitations for plant growth. Plants often overcome these nutritional constraints by their ability to form mutualistic associations with arbuscular mycorrhizal (AM) fungi. These symbiotic fungi assist host plants for the uptake of water and nutrients such as phosphate in return for carbohydrates (Govindarajulu et al. 2005; Harrison et al. 2002; Hawkins et al. 2000; Hodge et al. 2001; Javot et al. 2007). Nutrients are transferred from the fungus to host plants through intracellular structures known as arbuscules. AM fungi have existed in symbiosis with plants for more than 460 million years and probably allowed the colonization of land by plants (Simon et al. 1993). More than $85 \%$ of land plants, including angiosperms, gymnosperms, pteridophytes, and some bryophytes, can form

Corresponding author: Jean-Michel Ané; Telephone: +1.608.262.6457; Fax: +1.608.262.5217; E-mail: jane@wisc.edu

*The $\boldsymbol{e}$-Xtra logo stands for "electronic extra" and indicates that four supplementary figures and one supplementary table are published online. successful associations with AM fungi (Brundrett 2002, 2009; Pirozynski and Malloch 1975; Read et al. 2000; Smith and Gianinazzi-Pearson 1988; Wang and Qiu 2006). AM is prevalent among major agronomic crops for food, feed, and biofuel production.

AM colonization influences the root architecture of host plants (Gutjahr et al. 2009; Oláh et al. 2005; Paszkowski and Boller 2002; Price et al. 1989; Yano et al. 1996). Eudicots and monocots differ considerably in their root architecture, but AM fungi increase lateral root formation, root volume, root surface area, and average root diameter in both groups (Gutjahr et al. 2009; Harrison 2005; Hochholdinger and Zimmermann 2008; Hochholdinger et al. 2004; Kosuta et al. 2003; Monticelli et al. 2000; Subramanian et al. 2009). Besides these morphological changes, many genes are induced in plant roots in response to fungi (Gutjahr et al. 2008; Kistner et al. 2005; Liu et al. 2003; Siciliano et al. 2007). Medicago truncatula ENOD11 is an early reporter for both AM and Nod-factor signaling (Chabaud et al. 2002; Journet et al. 2001). Sinorhizobium meliloti induces ENOD11 expression mainly at the epidermal tissues lying behind the root tip and corresponding to the region of root-hair emergence and development, whereas AM fungi induce ENOD11 transiently in epidermal and cortical cells at the sites of hyphal penetration (Chabaud et al. 2002; Journet et al. 2001). Therefore, AM fungi induce changes at morphological and molecular levels in host plants.

The establishment of AM depends on a coordinated exchange of signals between symbiotic fungi and their host. Plant roots secrete strigolactones that induce branching in fungal hyphae prior to root colonization (Akiyama et al. 2005). Strigolactones also enhance spore germination and induce rapid changes in density, shape, and movement of mitochondria within AM fungi (Akiyama and Hayashi 2006; Besserer et al. 2006). Reciprocally, AM fungi produce diffusible factors often called Myc factors (by analogy with Nod factors), which are perceived by host plants. These diffusible factors increase lateral root formation and induce expression of ENOD11 in $M$. truncatula roots (Oláh et al. 2005; Kosuta et al. 2003). In addition, diffusible factors elicit a transient cytosolic calcium elevation in soybean cell cultures within a few minutes of inoculation, reminiscent of the early Nod factor-induced calcium influx (Navazio et al. 2007). Perinuclear calcium oscillations are also induced by these factors in $M$. truncatula root-hair cells, but the pattern of these oscillations is distinct from the calcium spikes induced by Nod factors (Kosuta et al. 2008).

Our understanding of the molecular processes required for AM signaling is mostly derived from genetic studies of the 
rhizobium-legume symbiosis. Several mutants in Medicago truncatula, Lotus japonicus, and pea are deficient for nodulation and AM, indicating the existence of a conserved symbiotic (Sym) pathway required for the establishment of both symbioses (Catoira et al. 2000; Kistner et al. 2005; Mitra et al. 2004b; Szczyglowski et al. 1998). At least eight genes belong to this Sym pathway: a receptorlike kinase with leucine-rich repeats, DMI2/SYMRK (Endre et al. 2002; Stracke et al. 2002); two ion channels localized to the nuclear envelope, DMI1/POLLUX and CASTOR (Ané et al. 2004; Imaizumi-Anraku et al. 2005; Peiter et al. 2007; Riely et al. 2007); three nucleopore-associated proteins, NUP85, NUP133, and NENA (Groth et al. 2010; Kanamori et al. 2006; Saito et al. 2007); a calcium calmodulindependent kinase, DMI3/CCaMK (Lévy et al. 2004; Mitra et al. 2004a); and a nuclear protein with coiled-coil domains, IPD3/CYCLOPS, which interacts with DMI3 (Messinese et al. 2007; Yano et al. 2008). While most of the mutants in the Sym pathway are blocked at the stage of hyphopodia formation, $c y$ clops mutants are characterized by inter- and intracellular hyphae with abnormal morphology and the formation of a few arbuscules (Yano et al. 2008). Besides legumes, several components of the Sym pathway are required for AM in rice as well (Banba et al. 2008; Chen et al. 2007, 2008, 2009; Gutjahr et al. 2008; Yano et al. 2008), suggesting that this pathway is ancestral to eudicots and monocots (Wang et al. 2010). Currently, the effects of these diffusible factors from AM fungi have not yet been described in rice or any other monocot.

Several responses induced in host plants by AM fungi are dependent on the Sym pathway. For example, lateral root stimulation and calcium oscillations in M. truncatula are dependent on DMII and DMI2 (Kosuta et al. 2008; Oláh et al. 2005). Expression of several AM-specific genes, such as $A M 3$, $A M 11, A M 14$, and $P T 11$, is also dependent on this pathway in rice (Gutjahr et al. 2008). However, induction of $A M 1$ and $A M 2$ expression by AM fungi in rice does not require the Sym pathway (Gutjahr et al. 2008). Transcriptome analyses in $L$. japonicus also suggest the existence of additional signaling pathways (Kistner et al. 2005). Although AM fungi-induced ENOD11 expression is dependent on DMI2 in M. truncatula, when the fungi are separated from the plant by a membrane, ENOD11 expression does not require the Sym pathway (Chabaud et al. 2002; Kosuta et al. 2003). Stimulation of lateral root formation in rice by Glomus intraradices is also independent of the Sym pathway (Gutjahr et al. 2009). Recently, it was shown in $M$. truncatula that two different signaling cascades exist for perception of AM fungal diffusible signal (Kuhn et al. 2010). Thus, in addition to the Sym pathway, a parallel pathway exists and mediates AM signaling in eudicots and monocots.

Regulation of symbioses by plant hormones and especially by ethylene is also a shared feature between legume nodulation and AM (Mukherjee and Ané, in press). Application of 1aminocyclopropane-1-carboxylic-acid (ACC), an ethylene precursor, decreases the number of infection events in root-nodule symbiosis, whereas application of aminoethoxyvinylglycine (AVG), an ethylene synthesis inhibitor, increases the number of infection threads (Oldroyd et al. 2001). In the ethyleneinsensitive mutant $s k l$ of $M$. truncatula, the number of aborted infection threads is lower than that in wild-type plants and the number of infection events is increased during nodulation (Oldroyd et al. 2001; Penmetsa and Cook 1997). The skl mutants are also characterized by increased mycorrhizal infections, suggesting that ethylene is involved in the negative regulation of infection initiation (Penmetsa et al. 2008). Transgenic L. japonicus lines with reduced ethylene sensitivity also display a higher number of infection threads than wild-type plants (Nukui et al. 2004). Similarly, root colonization of Medicago sativa by Glomus mosseae as well as colonization of Pisum sativum and Allium porrum by Glomus aggregatum is inhibited by ethylene (Azcon-Aguilar et al. 1981; Geil and Guinel 2002; Geil et al. 2001). In most plants, ethylene acts as a negative regulator of both bacterial and fungal entry into roots during endosymbioses. During root-nodule symbiosis, ethylene decreases the sensitivity of epidermal cells to Nod factors, which results in a reduced number of root hairs able to induce calcium spiking and express ENOD11 (Oldroyd et al. 2001). Ethylene may act upstream or at the level of calcium spiking in the Nod-factor signaling pathway. However, it is still not known how ethylene regulates responses to these factors.

In this study, we used a fast and efficient method to collect exudates from germinating AM spores in the absence of plant host. These germinating spore exudates (GSE) stimulated root development in rice (Oryza sativa), maize (Zea mays), and Medicago truncatula. GSE were also able to induce expression of ENOD11 in M. truncatula and of several symbiotic genes in rice. The genetic regulation of GSE-induced root architecture and gene expression was dependent on the common Sym pathway as well as another uncharacterized pathway. Finally, ethylene negatively regulated the induction of early symbiotic genes and root development in both rice and M. truncatula.

\section{RESULTS}

GSE stimulate changes

in root architecture of monocots and eudicots.

Using a technique adapted from Navazio and associates (2007), we have collected exudates from germinating spores of Glomus intraradices. In this study, we refer to this solution as GSE, which contains active molecules, among them Myc factors. First, we tested whether these GSE produced in the absence of the host plant could modify root architecture of monocots and eudicots. Root architecture in monocots differs considerably from eudicots (Hochholdinger and Zimmermann 2008; Hochholdinger et al. 2004; Rebouillat et al. 2008). For example, rice has two types of lateral roots, large lateral roots and fine lateral roots (Gutjahr et al. 2009; Rebouillat et al. 2008). The large lateral roots are preferred sites for fungal colonization, while the fine ones do not get colonized by AM fungi, as there are no cortical layers (Gutjahr et al. 2009; Rebouillat et al. 2008). When treated with GSE, the number of large lateral roots was significantly $(P<0.05)$ higher in rice 2 weeks posttreatment (Fig. 1A). However, the number of fine lateral roots in rice did not change significantly (Supplementary Fig. S1). This result indicated that effect of GSE on rice lateral roots was specific to the root type. This effect was also comparable to the effect of AM fungi on rice roots (Gutjahr et al. 2009). Other AM-relevant root parameters, such as root volume and root surface area, were increased significantly $(P<$ $0.05)$ in rice upon GSE treatment. Maize is also an economically important monocot that forms symbiotic associations with AM fungi and is a major model for the improvement of bioenergy crops (Carpita and McCann 2008). Therefore, we tested the effects of GSE on the maize root system. A 14-day old maize root system is characterized by the presence of primary roots, seminal roots, and shoot-borne crown roots, all bearing lateral roots (Hochholdinger and Zimmermann 2008; Hochholdinger et al. 2004). GSE treatment significantly $(P<$ 0.05 ) increased total number of lateral roots formed in the maize root system (Fig. 1B).

As control, 2 weeks after treatment with GSE, lateral root formation was significantly $(P<0.05)$ increased in $M$. truncatula (Fig. 1C). Therefore, even in the absence of the host plant, GSE contain compounds that are perceived by host plants and trigger responses similar to those described by Oláh and asso- 
ciates (2005). Root volume and root surface area were significantly $(P<0.05)$ increased in $M$. truncatula roots 2 weeks after treatment with GSE (Supplementary Fig. S2A and C). In summary, GSE released from Glomus intraradices in the absence of host plants modify root architecture in both monocots and eudicots.

\section{The genetic regulation of root architecture} by GSE differs between monocots and eudicots.

We tested whether or not components of the Sym pathway are required for GSE-induced changes in root architecture in rice and M. truncatula. Mutants in the Sym pathway have been identified in rice through reverse genetics and these mutants are required for AM symbiosis (Chen et al. 2007, 2008, 2009; Gutjahr et al. 2008). Therefore, we tested the effects of GSE on root architecture in rice mutants affected for CASTOR, POLLUX, DMI3, and IPD3 (Supplementary Table 1). A stimulation of development of large lateral roots by GSE was observed in pollux, castor, dmi3, and ipd 3 mutants 2 weeks after treatment $(P<0.05)$ (Fig. 2A). The percentage increase was comparable in the different mutants tested. Other GSE-induced root parameters, such as root volume and surface area, were also increased significantly in all these mutants $(P<0.05)$ (Supplementary Fig. S3B and D). Therefore, GSE-induced restructuring of root architecture in rice does not require $C A S$ TOR, POLLUX, DMI3, and IPD3.

As controls, we also tested the effect of GSE in $M$. truncatula mutants altered in three genes of the Sym pathway, i.e., DMI1, DMI2, and DMI3 (Catoira et al. 2000; Mitra et al. 2004b). GSE treatment did not elicit any increase of lateral root formation in $d m i 1$ and $d m i 2$ mutants 2 weeks posttreatment (Fig. 2B), indicating that DMII and DMI2 are required for GSE-induced lateral root stimulation. Root volume and root surface area also did not change significantly in $d m i l$ and $d m i 2$ mutants. In dmi3 mutants, however, lateral root forma- tion, root volume, and root surface area increased significantly upon GSE treatment $(P<0.05)$ (Fig. 2B). We also tested the effects of GSE on the M. truncatula $n f p$ and nspl mutants, which are affected in nodulation but present a wild-type AM phenotype. The number of lateral roots, root volume, and root surface area were significantly increased in these mutants, similar to the increase observed in wild-type plants $(P<0.05)$ (Fig. 2B). Therefore, NFP, DMI3, and NSP1 are not required for this response to GSE. These results with GSE were comparable to those observed in experiments in which a membrane separated the fungi from the plants (Oláh et al. 2005).

\section{GSE induce the expression of early symbiotic genes in rice and $M$. truncatula.}

AM fungi induce a remodeling of root architecture and expression of several symbiotic genes. Therefore, we analyzed the induction of early symbiotic genes by GSE in rice and $M$. truncatula as well as the control of this response by the Sym pathway. We tested expression of AM1, AM3, and AM11 $24 \mathrm{~h}$ after treatment with GSE in rice (Gutjahr et al. 2008). Expression of $A M 1, A M 3$, and $A M 11$ was induced as compared with roots that were not treated with GSE (Fig. 3A). This result indicated that GSE are sufficient to induce the expression of early symbiotic genes and that colonization by AM fungi or arbuscule formation is not required. However, it is possible that infection of plant roots by AM fungi is required for complete expression of these genes. GSE alone may not be able to induce a maximal expression of these genes. To determine if expression of these genes is controlled by components of the Sym pathway, we tested their expression in available rice AM mutants pollux, castor, dmi3, and ipd3. AM1 expression was detected in all the mutants, indicating that this induction does not require the Sym pathway (Fig. 3A). Expression of $A M 3$ was only detected in ipd 3 mutants and $A M 11$ expression was not observed in any of the mutants (Fig. 3A). Therefore, the
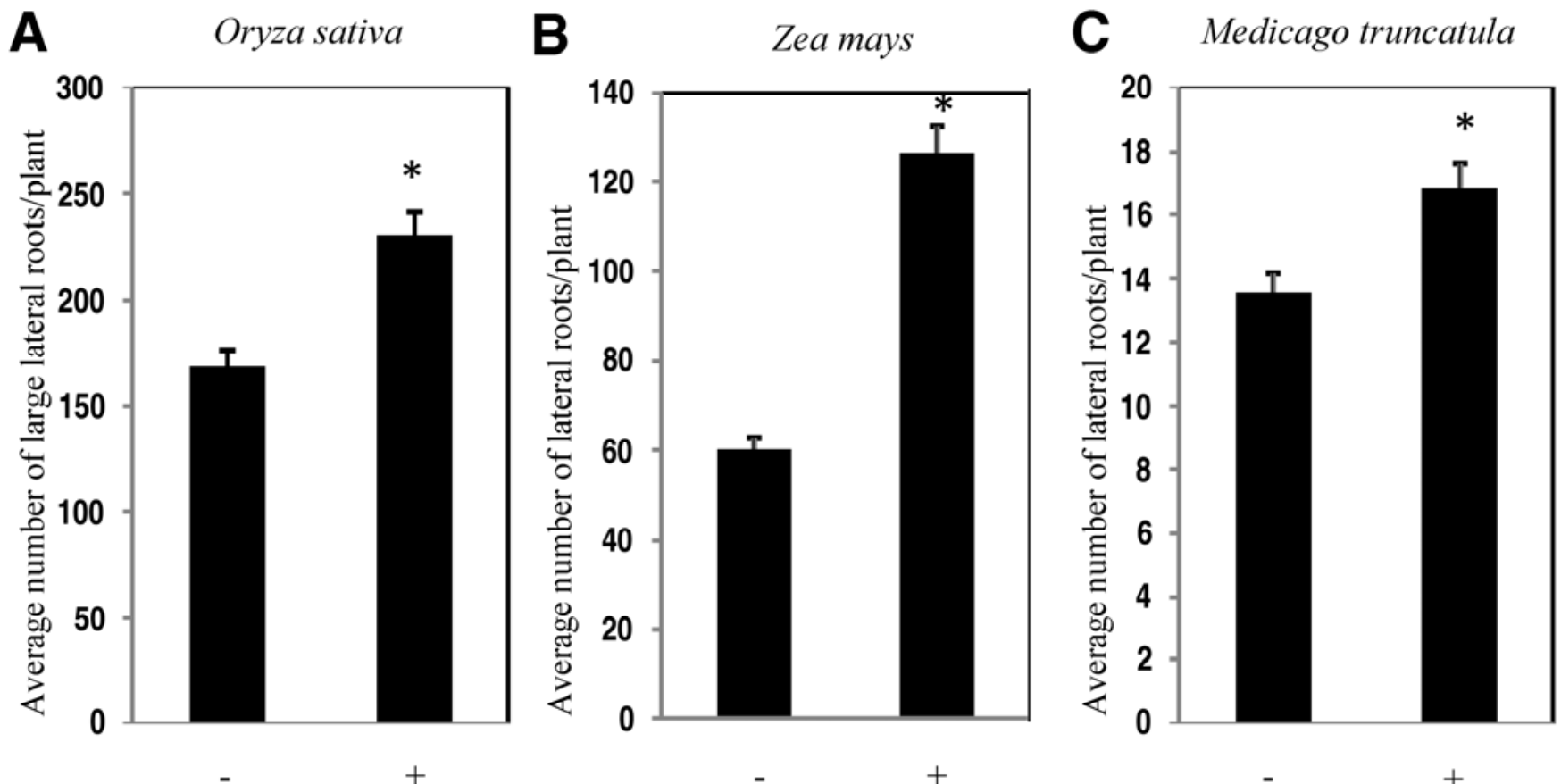

Fig. 1. Germinating spore exudates (GSE) increase lateral root formation in monocots and eudicots. Comparison of average number of lateral roots per plant in wild-type A, rice (O. sativa), B, maize (Z. mays), and C, Medicago truncatula with (+) and without (-) GSE treatment. In rice, large lateral root formation was increased. In maize, total number of lateral roots borne on primary roots, seminal roots, and shoot-borne crown roots were increased. Plants were treated for $24 \mathrm{~h}$, and the lateral root numbers were calculated 2 weeks posttreatment. - indicates plants not treated with GSE and + indicates plants treated with GSE. Values are means \pm standard error $(n=45)$. Values denoted with an asterisk $(*)$ are significantly different at a 0.05 confidence level. Data was generated from at least three independent experiments with 15 plants per treatment. 
Sym pathway is required for the GSE-induced expression of $A M 11$ and, to an extent, for $A M 3$ expression. These results are consistent with those reported upon AM colonization (Gutjahr et al. 2008). Therefore, in addition to the Sym pathway, one or more parallel pathways exist to activate early symbiotic gene expression in response to GSE.

As controls, we also tested ENOD11 expression in M. truncatula in response to GSE treatment. We observed ENOD11 expression in the $M$. truncatula A17 homozygous line expressing the pMtENOD11-gusA fusion (line L416) (Journet et al. 2001) $24 \mathrm{~h}$ after treatment with GSE (Fig. 3B). More than $80 \%$ of these plants displayed ENOD11 expression (Table 1). ENOD11 expression was observed throughout the root vasculature, in inner cortical cells around the vasculature, and in epidermal cells at the zone of root-hair growth (Fig. 3B and C).

\section{A}

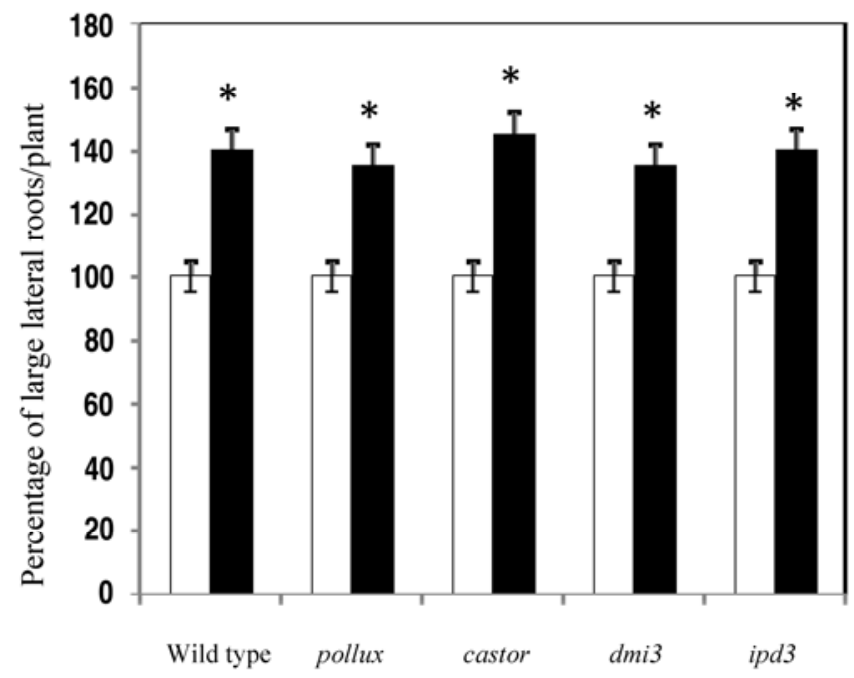

B

\section{Medicago truncatula}

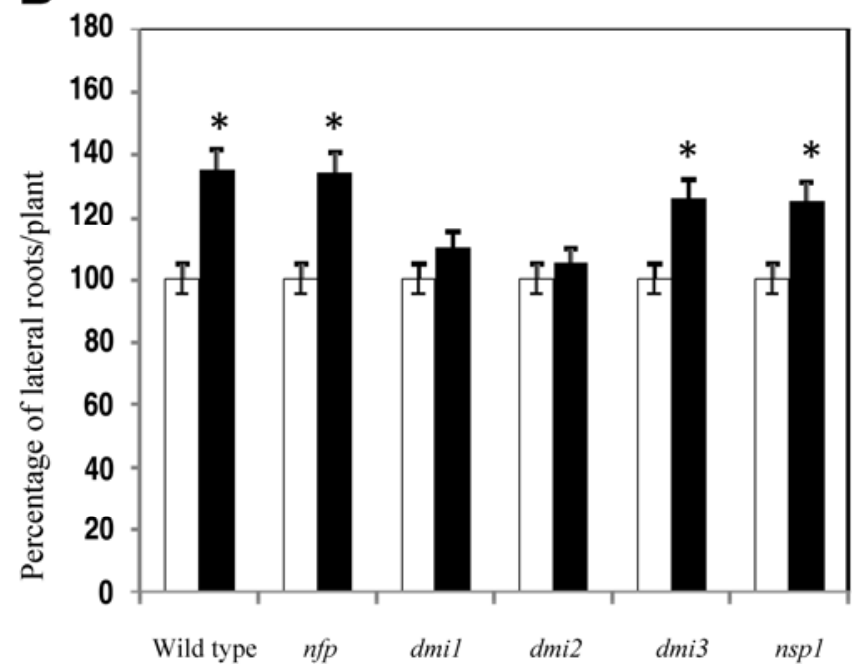

Fig. 2. Germinating spore exudates (GSE) regulate lateral root formation differentially between monocots and eudicots. Comparison of average number of lateral roots per plant in wild-type A, rice and B, Medicago truncatula and in their symbiotic mutants, respectively, with and without GSE treatment. Means are presented as percentage of the control value (no GSE). Plants were treated for $24 \mathrm{~h}$, and the lateral root numbers were calculated 2 weeks posttreatment. White bars indicate plants treated without GSE and black bars indicate plants treated with GSE. Values are means \pm standard error $(n=45)$. Values denoted with an asterisk $(*)$ are significantly different at a 0.05 confidence level. Data was generated from at least three independent experiments with 15 plants per treatment.
The intensity of ENOD11 expression was variable in the epidermal cells, as some cells showed more $\beta$-glucuronidase (GUS) activity than others (Fig. 3C). In older root regions, ENOD11 expression was mostly induced in the vasculature and inner cortical cells (Fig. 3D). In these regions, epidermal expression was not observed at all. Control roots displayed some constitutive ENOD11 expression in the vasculature, at the sites of lateral root formation, and in root tips, as described previously (Journet et al. 2001). These results indicate that GSE contain compounds that are sufficient to induce ENOD11 expression in inner cortical cells and in some epidermal cells.

To determine if the Sym pathway plays a role in GSE-induced ENOD11 expression, we tested transgenic $\mathrm{Nod}^{-} / \mathrm{Myc}^{-}$mutants (dmil, dmi2, dmi3) and $\mathrm{Nod}^{-} / \mathrm{Myc}^{+}$mutants (nfp, nspl) carrying pMtENOD11-gusA with GSE treatment. These mutants have been genotyped as homozygous by phenotypic analysis of their progeny. We analyzed ENODI1 expression in two DMII mutant alleles, C71 (dmil-1) and B129 (dmil-2) (Ané et al. 2004). Of the C71 plants, 25\% displayed ENOD11 expression (Table 1). Absolutely no ENOD11 expression was observed in the B129 allele, indicating that this allele strongly interfered with the action of GSE. Presence of the pMtENOD11-gusA transgene in this allele was confirmed through the constitutive ENOD11 expression in the leaf vasculature. Transgene expression was detected in less than $15 \%$ of TR25 (dmi2-1) lines (Table 1). The transgenic dmil-1, dmil-2, and dmi2-1 lines were confirmed to be homozygous for the $\mathrm{p} E N O D 11$-gusA insertion by genotyping (Supplementary Fig. S4A). In $d m i 3, n f p$, and $n s p l$ mutants, GSE were able to induce ENOD11 expression at levels similar to wild-type plants, indicating that these genes are not required for ENOD11 expression. We also performed quantitative real-time reverse transcription-polymerase chain reaction (RT-PCR) to confirm ENOD11 expression upon GSE treatment in the different symbiotic mutants of M. truncatula. ENOD11 expression was not induced in C71 (dmil-1), B129 (dmil-2), and TR25 (dmi2-1) mutant alleles upon GSE treatment (Fig. 3E). The rare ENOD11 expression in C71 and TR25 alleles observed by GUS staining was not detected by quantitative RT-PCR. This observation indicates that activation of ENOD11 can also occur by a Sym-independent pathway and is probably controlled by unidentified environmental factors. These results also confirmed that ENOD11 expression was induced upon GSE treatment in C31 (nfp-1), TRV25 (dmi3-1), and C54 (nspl-2) mutant alleles (Fig. 3E). These findings provide new insights into the effects of GSE on ENOD11 expression in M. truncatula (Chabaud et al. 2002; Kosuta et al. 2003). DMI1 and DMI2 are required for a full response to GSE, whereas NFP, DMI3, and NSP1 are not. However, some signaling can obviously take place in the absence of DMII and DMI2, which confirms that requirement for these genes is not stringent for ENOD11 expression.

Table 1. Germinating spore exudates (GSE)-induced ENOD11 expression in wild type and symbiotic mutants of Medicago truncatula ${ }^{\mathrm{a}}$

\begin{tabular}{lcc}
\hline Gene & Mutant allele & $\begin{array}{c}\text { Plants displaying } \\
\text { ENOD11 expression (total plants) }\end{array}$ \\
\hline Wild-type A17 & - & $29(35)$ \\
NFP & C31 & $14(15)$ \\
DMI1 & C71 & $4(16)$ \\
& B129 & $0(24)$ \\
DMI2 & TR25 & $2(16)$ \\
DMI3 & TRV25 & $8(8)$ \\
NSP1 & C54 & $9(12)$ \\
\hline
\end{tabular}

${ }^{\text {a }}$ Comparison of GSE-induced ENOD11 expression in symbiotic mutants of Medicago truncatula. Four-day-old plants were treated with GSE for $24 \mathrm{~h}$ and were stained for GUS activity immediately posttreatment. For each plant genotype, data is generated from at least two independent experiments. 

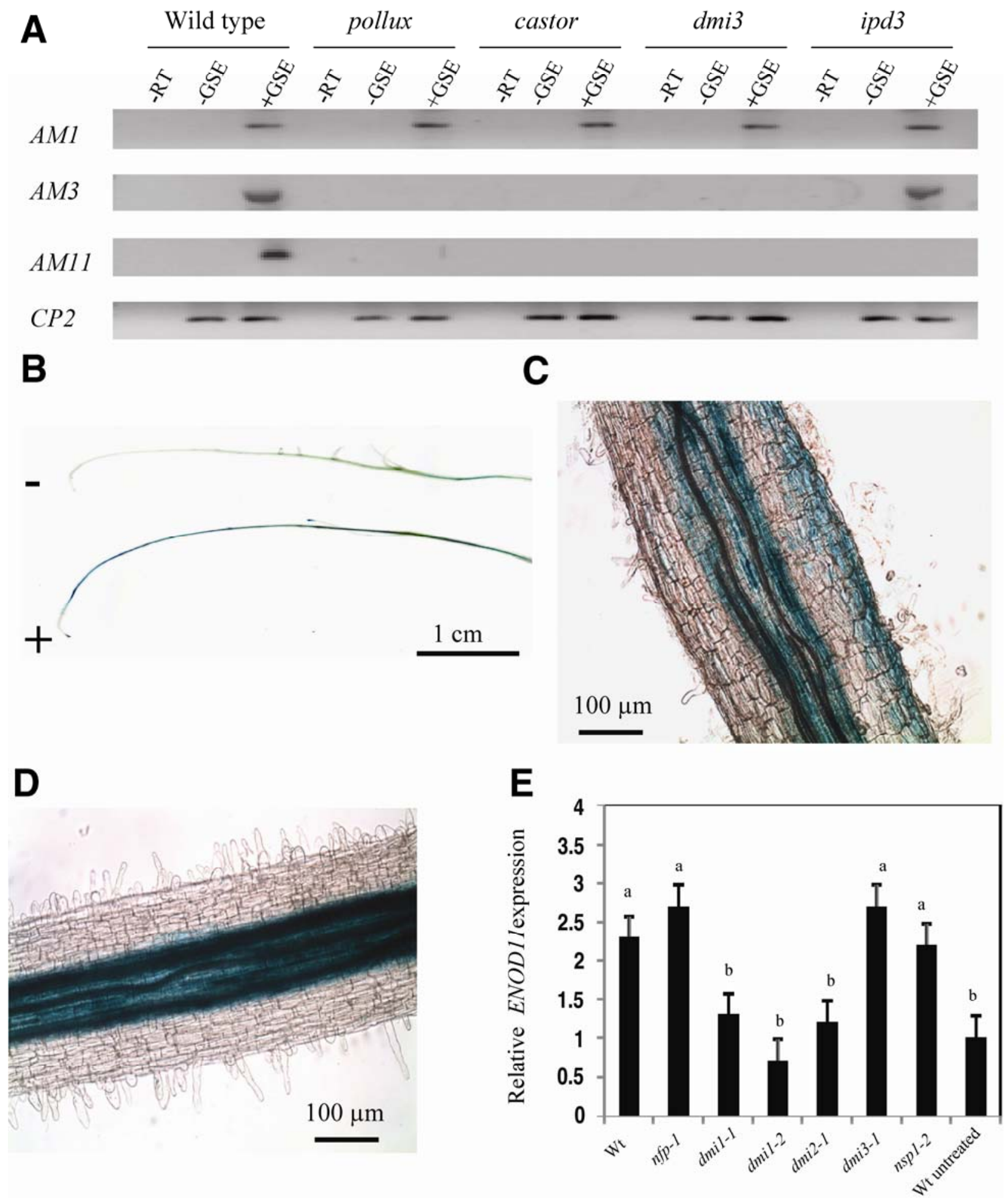

Fig. 3. Germinating spore exudates (GSE) induce expression of early symbiotic genes in Medicago truncatula and rice. A, Reverse transcription-polymerase chain reaction (RT-PCR) of early induced rice genes $(A M 1, A M 3, A M 11)$ in wild-type rice and in its symbiotic mutants $24 \mathrm{~h}$ posttreatment with and without GSE. The induction of the genes is compared with that in plants not treated with GSE and non-reverse transcribed (-RT) RNA. CYCLOPHILIN2 (CP2) is the internal control for these experiments. Data are from two independent experiments. B, ENOD11 expression occurs in the zone of root development in the M. truncatula A17 homozygous line expressing the pMtENOD11-gusA gene fusion following GSE treatment. - indicates plants not treated with GSE and + indicates plants treated with GSE. C and D, Semithin sections $(50 \mu \mathrm{m})$ of primary roots expressing ENOD11 in response to GSE in the proximal (C) and distal (D) parts of the root. Expression is observed in the cortex and vasculature of both regions, but epidermal expression was restricted to the proximal region. The blue coloration shows $\beta$-glucuronidase (GUS) activity due to ENOD11 expression. Four-day-old plants were treated with GSE for $24 \mathrm{~h}$ and were stained for GUS activity immediately posttreatment. No GUS activity was detected in these regions of the root in untreated plants. Data were obtained from at least five independent experiments, with each repetition consisting of at least six plants. E, Quantitative RT-PCR demonstrating relative expression of ENOD11 in wild-type M. truncatula and in its symbiotic mutants $24 \mathrm{~h}$ posttreatment with and without GSE. The induction of ENOD11 expression is compared with that in plants not treated with GSE. Data are the average of three biological replicates. MtACTIN was used as the internal control primer. All error bars represent standard error. Values denoted with different letters are significantly different at a 0.05 confidence level. 


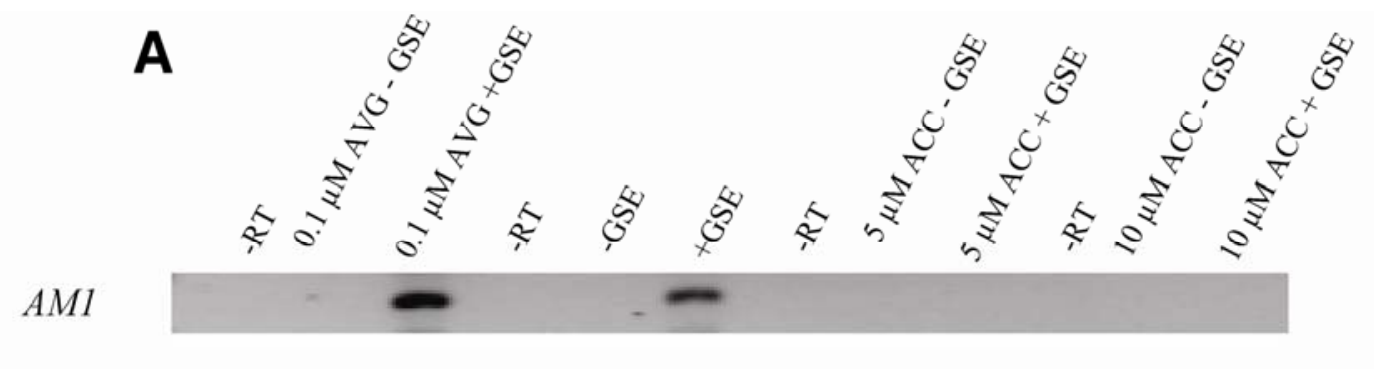

$A M 3$

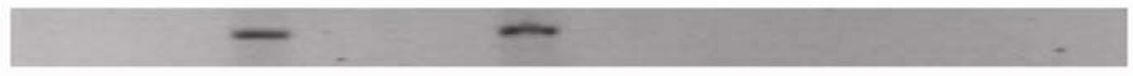

AM11

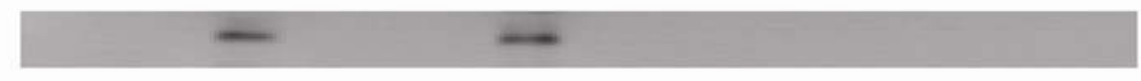

\section{$C P 2$}

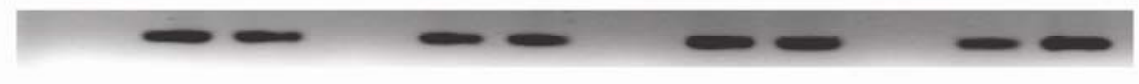

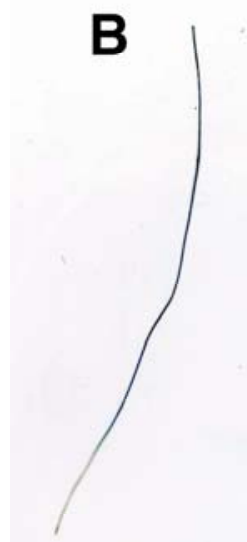

$0.1 \mu \mathrm{M} A V G+\mathrm{GSE}$

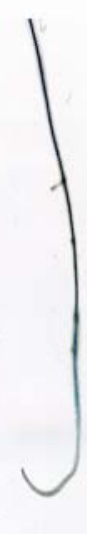

GSE

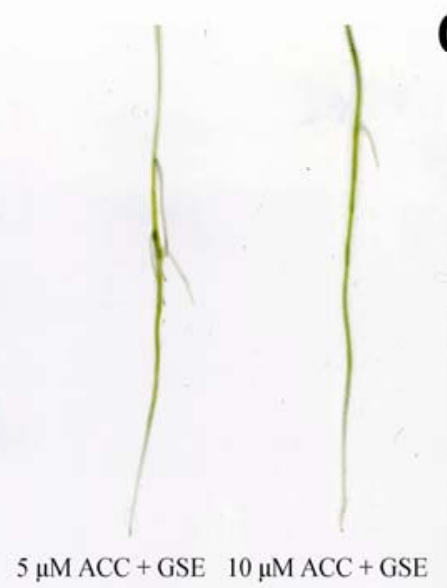

C

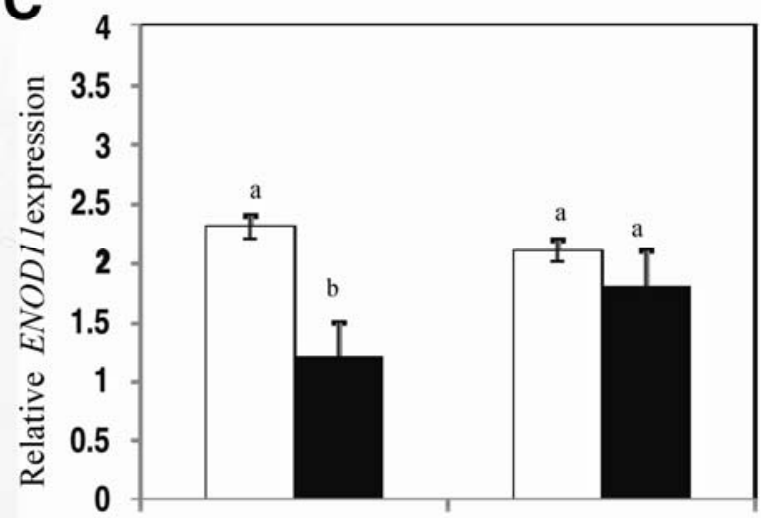

Wild type

skll-I

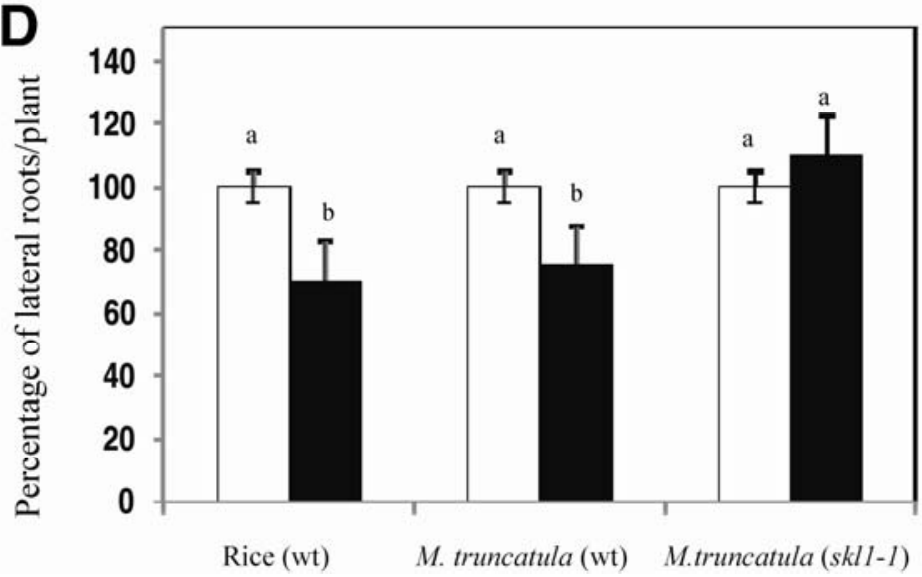

Fig. 4. Ethylene inhibits germinating spore exudates (GSE) induced expression of early symbiotic genes and root development in rice and $M$ edicago truncatula. A, Comparison of GSE-induced $A M 1, A M 3$, and $A M 11$ expression in rice in the presence of either $0.1 \mu \mathrm{M}$ aminoethoxyvinylglycine (AVG), $5 \mu \mathrm{M} 1$ aminocyclopropane-1-carboxylic-acid (ACC), or $10 \mu \mathrm{M}$ ACC by reverse transcription-polymerase chain reaction (RT-PCR). The induction of the genes is compared with that in 4-day-old plants treated with GSE alone and with either $0.1 \mu \mathrm{M}$ AVG, $5 \mu \mathrm{M}$ ACC, or $10 \mu \mathrm{M}$ ACC. The plants were treated for 24 h. Non-reverse transcribed (-RT) RNA is included as negative control. CYCLOPHILIN2 (CP2) is the internal control for these experiments. Data represented are from two independent experiments. B, Comparison of GSE-induced ENOD11 expression in a M. truncatula A17 homozygous line expressing the $\mathrm{p} M t E N O D 11$-gusA gene fusion in the presence of either $0.1 \mu \mathrm{M}$ AVG, $5 \mu \mathrm{M}$ ACC, or $10 \mu \mathrm{M}$ ACC. The blue coloration shows $\beta$-glucuronidase (GUS) activity due to ENOD11 expression. Control plants were treated with GSE in the absence of AVG or ACC. Four-day-old plants were treated for 24 h with GSE in the presence of either $0.1 \mu \mathrm{M}$ AVG, $5 \mu \mathrm{M}$ ACC, or $10 \mu \mathrm{M}$ ACC and were stained for GUS activity immediately posttreatment. Data represented are from two independent experiments, with each experiment containing at least six plants per treatment. C, Quantitative RT-PCR demonstrating relative expression of ENOD11 in wild-type M. truncatula and in skl1-1 mutant $24 \mathrm{~h}$ posttreatment with GSE in the absence or presence of $10 \mu \mathrm{M}$ ACC. The induction of ENOD11 expression is compared with that in plants not treated with GSE. Black bars indicate GSE treatment in the presence of $10 \mu \mathrm{M}$ ACC, while white bars indicate GSE treatment with no ACC. Data are the average of three biological replicates. MtACTIN was used as the internal control primer. All error bars represent standard error. Values denoted with different letters are significantly different at a 0.05 confidence level. D, Comparison of the average number of lateral roots per plant in wild-type rice, in wild-type $M$. truncatula, and in $M$. truncatula skl1-1 mutant upon GSE treatment in the presence or absence of $10 \mu \mathrm{M}$ ACC for $24 \mathrm{~h}$. Means are presented as the percentage of the control value (no ACC). Plants were treated for $24 \mathrm{~h}$, and the lateral root numbers were calculated 2 weeks posttreatment. White bars represent GSE treatment without ACC, while black bars represent GSE treatment in the presence of $10 \mu \mathrm{M}$ ACC. Values denoted with different letters are significantly different at a 0.05 confidence level. 


\section{GSE-induced developmental and molecular responses} are negatively regulated by ethylene.

Plant hormones like ethylene are key regulators of legume nodulation and AM (Geil and Guinel 2002; Mukherjee and Ané in press). To test the effect of ethylene on symbiotic gene expression in rice, we treated rice plants with GSE for $24 \mathrm{~h}$ in the presence of either the ethylene synthesis inhibitor (AVG) or the ethylene synthesis precursor (ACC). In the presence of 5 or $10 \mu \mathrm{M}$ ACC, expression of $A M 1, A M 3$, and $A M 11$ was not induced by GSE (Fig. 4A). Expression of these genes was still induced by GSE in the presence of $0.1 \mu \mathrm{M}$ AVG (Fig. 4A).

Similarly, to test the effect of ethylene on GSE-induced ENOD11 expression, transgenic M. truncatula pMtENOD11gusA plants were treated with GSE for $24 \mathrm{~h}$ in the presence of AVG and ACC. In the presence of $0.1 \mu \mathrm{M}$ AVG, ENOD11 expression was normal (Fig. 4B). However, ENOD11 was not induced in plants treated with 5 or $10 \mu \mathrm{M}$ ACC (Fig. 4B). In both cases, nonsymbiotic ENOD11 expression in root tips was still observed. Using quantitative RT-PCR, we confirmed that $10 \mu \mathrm{M}$ ACC inhibited GSE-induced ENOD11 expression in wild-type A17 roots (Fig. 4C). Our analyses also included the ethylene-insensitive $M$. truncatula mutant skl1-1. GSE-induced ENOD11 expression in skl1-1 mutants was comparable to its induction levels in wild-type plants. But unlike in wild-type plants, induction of ENOD11 expression was not inhibited in presence of $10 \mu \mathrm{M}$ ACC in skl1-1 (Fig. 4C). In summary, ethylene acts as a negative regulator of early gene expression induced by GSE in both M. truncatula and rice.

We also analyzed the effect of ethylene on GSE-induced root development in rice and $M$. truncatula. In the presence of $10 \mu \mathrm{M}$ ACC, GSE-induced large lateral root formation was significantly inhibited in rice (Fig. 4D). Similarly, in $M$. truncatula, $10 \mu \mathrm{M}$ ACC inhibited the effect of GSE on lateral root formation. As expected, addition of ethylene did not affect lateral root formation in skll-1 (Fig. 4D). Thus, ethylene negatively regulates GSE-induced root development in both monocots and eudicots.

\section{DISCUSSION}

In this study, we used a technique derived from the one described by Navazio and associates (2007) to generate exudates from germinating spores of AM fungi in the absence of host plant. The GSE are most likely to contain biologically active Myc factors in addition to other unknown molecules. We tested the responses of rice, maize, and $M$. truncatula to these fungal signals. This treatment increased lateral root formation, root volume, and root surface area in both rice and $M$. truncatula. However, genetic regulation of root architecture was different between monocots and eudicots. GSE induced expression of early symbiotic genes in rice and $M$. truncatula after $24 \mathrm{~h}$. The use of mutants in rice and M. truncatula showed that induction of symbiotic genes is dependent on the Sym pathway as well as on another uncharacterized pathway. Early symbiotic gene expression and root development was also negatively regulated by ethylene in rice and M. truncatula.

AM fungi elicit multiple responses in host plants even when separated by a fungus-impenetrable membrane. These responses include stimulation of lateral root formation, induction of ENOD11 expression, and calcium oscillations in M. truncatula roots (Kosuta et al. 2003, 2008; Oláh et al. 2005). We showed that exudates from germinating spores isolated in absence of host plant are sufficient to enhance root development and induce early symbiotic gene expression in both monocots and eudicots. Production of these symbiotic signals is, therefore, an innate property of the fungus and do not require the presence of a host. Similarly, strigolactones and flavonoids are plant signals released in the rhizosphere even in the absence of AM fungi (Akiyama et al. 2005; Besserer et al. 2006; Peters et al. 1986; Rolfe 1988; Stougaard 2000). Therefore, a basal level of symbiotic signals is produced by both AM fungi and host plants, and this does not require the presence of symbiotic partners. At the same time, it is possible production of these symbiotic signals may be up- or downregulated by plant signals such as strigolactones or flavonoids. Unfortunately, the host gene-expression or root-development phenotypes that we analyzed in this study cannot be used as quantitative bioassays for Myc factors present in the GSE. Quantifying Myc-factor production will probably require the identification of active molecules.

We have shown, for the first time, responses of monocots to GSE. These signals probably prepare host roots (monocots and eudicots) for subsequent colonization by AM fungi and successful symbiosis. Genetic analyses of GSE-induced developmental responses indicated that similarities and differences exist between monocots and eudicots. In M. truncatula and rice, root development stimulation is independent of $C C a M K / D M I 3$ (Fig. 2). DMII and DMI2 are required for root-architecture stimulation in M. truncatula, but the DMI1 orthologs (POL$L U X$ and CASTOR) in rice are not necessary for similar responses in rice. This result indicates that differences exist in the function of these ion channels between the two species. This result also correlates with the induction of lateral root formation in rice by AM fungi, which is independent of the Sym pathway (Gutjahr et al. 2009). Since DMII and DMI2 are required for the induction of calcium spiking, the root developmental responses to GSE may require calcium spiking in $M$. truncatula but not in rice. Interestingly, it is still unknown if calcium spiking is induced in monocots in response to AM fungi. Once a dmi2/symrk mutant is identified in rice, it will be interesting to test the role of this gene in response to GSE. Existence of an alternative calcium perception system apart from DMI3 in rice is also a possibility. Major differences exist in root architecture and development between eudicots and monocots (Hochholdinger et al. 2004; Rebouillat et al. 2008). It seems logical that GSE might modify root architecture through different pathways in monocots and eudicots (Fig. 2).

Regarding gene expression, ENOD11 expression was observed in inner cortical cells and in some epidermal cells in response to GSE (Fig. 3C). Epidermal expression was only detected in the zone of growing root hairs. The cell-specific expression pattern of this early symbiotic gene suggests that these signals are specifically preparing some plant cells for colonization by AM fungi. However, it is notable that cells outside of these ENOD11-expression regions can be infected by AM fungi. Local delivery of these signals might also play a role in the preparation of specific cells for AM infection (Genre et al. 2008).

In our study, $n f p, d m i 3$, and $n s p l$ mutants responded like wild-type plants to GSE, confirming that these genes are not required for ENOD11 expression in response to GSE (Table 1). C71 (dmil-1) and TR25 (dmi2-1) mutants showed a reduced ENOD11 induction. However, the B129 allele (dmi1-2) was totally blocked for ENOD11 induction. The stronger phenotype observed with $d m i 1-2$ as compared with $d m i 1-1$ may be due to the semidominant negative nature of this allele (Peiter et al. 2007). Analyses of quantitative real-time RT-PCR data also indicated that ENOD11 expression was not induced in C71 (dmil-1), B129 (dmil-2), or TR25 (dmi2-1) mutants upon GSE treatment (Fig. 3E). It has been reported previously that ENOD11 expression is induced by a Sym-independent pathway when AM fungi are separated from the plants by a membrane (Kosuta et al. 2003). In the membrane-separated experiments, ENOD11 expression was mostly induced in tertiary roots ( $25 \%$ of the total number of roots tested) of 14-day-old 
M. truncatula. The transgene was never expressed in the primary roots (Kosuta et al. 2003). Thus, the differences observed between our results and those from Kosuta and associates (2003) can be attributed to the developmental stage at which the plant roots were treated with these diffusible signals and were analyzed for ENODI1 expression. Our results confirm the role of a Sym-independent pathway and also reveal a role for DMII and DMI2 in this process (Table 1; Fig 3E). Our observation correlates with the requirement of the Sym pathway for ENOD11 expression upon colonization by AM fungi (Chabaud et al. 2002). Thus, GSE activate multiple pathways to induce symbiotic gene expression in M. truncatula. It is also possible that multiple signaling molecules exist in GSE, each of them eliciting different pathways, and this hypothesis could be tested after identification of active molecules (Myc factors) in the GSE. In rice, activation of $A M 1, A M 3$, and $A M 11$ expression indicates that GSE can also induce early molecular responses in monocots (Fig. 3A). Mutant analyses revealed that $A M 1$ is induced independently of the Sym pathway, whereas $A M 3$ and $A M 11$ induction is dependent on the Sym pathway (Fig. 3A). However, induction of $A M 3$ expression was independent of IPD3, suggesting the existence of an alternative signaling pathway downstream of calcium spiking. These results indicate the existence of multiple pathways mediating responses to GSE in monocots as well. Induction of these early symbiotic genes can now be utilized as markers to identify new signaling components that are dependent on or independent of the Sym pathway.

By modulating levels of ethylene, we have shown that this plant hormone has a strong inhibitory effect on early symbiotic gene expression and root development in response to GSE (Fig. 4). This inhibition was observed in both M. truncatula and rice and is consistent with the existence of a conserved regulatory mechanism between eudicots and monocots. In root nodule symbiosis, ethylene has been implicated at the level of or upstream of calcium spiking in the regulation of Nod-factor signaling (Oldroyd et al. 2001). Ethylene might play a similar role in response to mycorrhizal Myc factors. Inhibition of $A M 1$ induction in rice indicates that ethylene also regulates a nonSym pathway (Fig. 4A). At the morphological level, ethylene plays multiple roles in regulating root architecture. For instance, lateral root formation is inhibited by ethylene, but ethylene also stimulates the development of adventitious roots (Kieber et al. 1993; Negi et al. 2008, 2010). The GSE-induced changes in root architecture are also negatively regulated by ethylene in both monocots and eudicots. Thus, ethylene seems to act as a negative regulator of GSE-induced molecular and developmental responses across angiosperms.

Therefore, following the perception of mycorrhizal signals, multiple responses are triggered in host plants. These responses are controlled by the Sym pathway and also by another stilluncharacterized pathway. In eudicots, root development stimulation is dependent to some extent on the Sym pathway, whereas in monocots, it seems independent of it. Induction of symbiotic genes in $M$. truncatula and rice is also dependent on the Sym pathway and on another pathway. All these responses are regulated by ethylene, and ethylene acts as a negative regulator of both pathways.

In this study, we used a fast and efficient procedure to generate exudates from germinating AM spores. From a practical point of view, such exudates can be used directly for plant growth stimulation and root enhancement. Other plant responses need to be characterized in order to determine additional benefits or shortcomings associated with such treatments in the field. Since these are released by AM fungi in the absence of host plants, it will be important to test the effect of such molecules on mycorrhizal helper bacteria, on soil-borne plant patho- gens, and, more generally, on soil microbial communities. Identifying mycorrhizal signals and engineering plant responses to these signals appears to be a promising strategy to increase yields over a wide range of crops for food, feed, and biofuel production.

\section{MATERIALS AND METHODS}

\section{Plant material and growth conditions.}

For root architecture experiments, Medicago truncatula Jemalong (A17), C31 (nfp-1), B129 (dmi1-2), TR25 (dmi2-1), TRV25 (dmi3-1), C54 (nspl-2), and skll-1 genotypes were used (Amor et al. 2003; Ané et al. 2004; Endre et al. 2002; Lévy et al. 2004; Mitra et al. 2004a; Penmetsa and Cook 1997; Smit et al. 2005). For MtENOD11 expression assays, Jemalong L416, a transgenic wild type with a single copy fusion between the MtENOD11 promoter and gusA gene was used (Journet et al. 2001). Mutant studies were performed with the same transgene in genetic background of C31 (nfp-1), B129 (dmi1-2), C71 (dmil-1), TR25 (dmi2-1), TRV25 (dmi3-1), and C54 (nsp1-2) mutants. Oryza sativa cvs. Nipponbare and Hwayoung, Tos17 insertion lines in POLLUX (line NC6423), in DMI3 (line NF8513), in IPD3 (line NC0263), and a T-DNA insertion line in CASTOR (line C04353) were used for rootarchitecture and gene-expression experiments (Chen et al. 2007, 2008, 2009). Zea mays cv.B73 seeds were also used in this study. M. truncatula seeds were scarified with an 8-min treatment with concentrated sulfuric acid, were surface-sterilized with a $2.4 \%(\mathrm{wt} / \mathrm{vol})$ calcium hypochlorite solution for 1 min, were synchronized by imbibition at $4{ }^{\circ} \mathrm{C}$ for $48 \mathrm{~h}$, and were germinated by incubating at room temperature overnight. $O$. sativa and $Z$. mays seeds were surface-sterilized twice with a $2.4 \%$ (wt/vol) calcium hypochlorite solution for $15 \mathrm{~min}$, were washed extensively with sterile water, and were pregerminated in sterile water for 5 days at room temperature in the dark. M. truncatula and $O$. sativa plants were initially grown on Hoagland's media plates supplemented with $20 \mu \mathrm{M}$ phosphate for 4 days. Z. mays seedlings were wrapped in brown germination paper (Anchor Paper, St. Paul, MN, U.S.A.), as a cigar roll, and were allowed to grow for 4 days. The cigar rolls were soaked vertically in a 2-liter glass beaker filled with low phosphorus $(20 \mu \mathrm{M})$ Hoagland's solution. All plants were grown in a growth chamber with a $16-\mathrm{h}, 22^{\circ} \mathrm{C}$ day and $8-\mathrm{h}$, $24^{\circ} \mathrm{C}$ night cycle and 150 to $200 \mu \mathrm{mol} \mathrm{m} \mathrm{m}^{-2} \mathrm{~s}^{-1}$ light intensity. The relative humidity was $65 \%$.

\section{Preparation of GSE from Glomus intraradices.}

Sterile Glomus intraradices spore suspension (IRBV'95 Mycorise ASP; Premier Tech Biotechnologies, Rivière-duLoup, Quebec, Canada) was washed three times with sterile distilled water by centrifugation at $3,000 \times g$ for $10 \mathrm{~min}$. Germination was induced by placing the spores in sterile distilled water at $25^{\circ} \mathrm{C}$ in the dark for 7 days. Following germination, the spores were separated via filtration through a $0.2-\mu \mathrm{m}$ nylon filter (Fisher Scientific). Absence of $G$. intraradices spores or hyphae was confirmed by observing an aliquot of the filtrate under a light microscope.

\section{Plant treatment with GSE.}

Seedlings of $M$. truncatula and $O$. sativa were treated with GSE for $24 \mathrm{~h}$ in the dark. All seedlings were 4 days old and each seedling from all species tested was treated with GSE prepared from 250 fungal spores. Control experiments were performed by soaking 4-day-old seedlings in sterile Hoagland's solution without any GSE for the same duration of time. For root-architecture experiments, $M$. truncatula and $O$. sativa plants were transferred back to Hoagland's media plates in the 
growth chamber following treatment. Z. mays seedlings were transferred onto cigar rolls following treatment. For gene-expression studies, roots were harvested immediately after treatment or were stained for GUS activity. For gene-expression studies in the presence of ethylene, either $0.1 \mu \mathrm{M}$ AVG, $5 \mu \mathrm{M}$ $\mathrm{ACC}$, or $10 \mu \mathrm{M}$ ACC was included in the liquid medium containing GSE. These treatments were also for $24 \mathrm{~h}$.

\section{Root-architecture measurements and statistical analysis.}

Root architecture was analyzed with the WinRHIZO image analysis system (V4.1c; Régent Instruments Canada, Inc., Ottawa, Canada). Using this system, root surface area and root volume was automatically analyzed. Lateral roots were counted under a dissecting microscope. Significance results $(P$ values) were calculated using Student's $t$-test and analysis of variance in Kaleidagraph (Synergy Software, Reading, PA, U.S.A.).

\section{Histochemical localization of GUS activity.}

$M$. truncatula plants carrying the MtENOD11 promoter driving the expression of the gusA gene were stained for GUS activity at $37^{\circ} \mathrm{C}$ for $6 \mathrm{~h}$ with $2 \mathrm{mM}$ 5-bromo-4-chloro-3-indolyl- $\beta$-D-glucuronic acid, $50 \mathrm{mM}$ sodium phosphate ( $\mathrm{pH} 7.2), 1$ $\mathrm{mM}$ potassium ferrocyanide, and $1 \mathrm{mM}$ potassium ferricyanide with $5 \mathrm{mM}$ EDTA, as described previously (Journet et al. 1994). Prior to staining at $37^{\circ} \mathrm{C}$, the roots were vacuum-infiltrated for 10 to $15 \mathrm{~min}$ in the GUS staining solution at room temperature.

For histological observations, stained root segments were embedded in $4 \%$ (wt/vol) low melting-temperature agar (type III; Sigma-Aldrich, St. Louis). Semithin sections $(50 \mu \mathrm{m})$ were prepared using a Leica VT1000P manual vibrating microtome (The Vibratome Company, St. Louis) and were observed immediately under a bright-field microscope.

\section{Genotyping the pENOD11-gusA insertion.}

Genomic DNA was extracted from the different $M$. truncatula transgenic plants using Qiagen DNeasy plant mini kit (Chatsworth, CA, U.S.A.) according to the manufacturer's instruc-

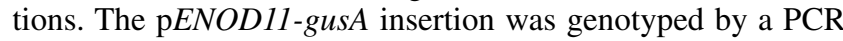
strategy that amplified two different products depending on the presence of the insertion in the genome. The primer sequences used were 5'-TTTCATACCTTTTTAGTTGCGTGGG-3' (WT Forward), 5'-CAACAGGAAGGAGCCAAGTTGAA-3' (WT Reverse), and 5'-GGGAATTTATGGAACGTCAGTGGA-3' (RB T-DNA Reverse) (O. André, personal communication). Plants homozygous for the $\mathrm{pENOD11-gusA}$ insertion show an amplification of 513 bp (WT Forward and RB T-DNA Reverse), the wild type (nontransgenic) shows an amplification of $1,180 \mathrm{bp}$ (WT Forward and WT Reverse), and the heterozygotes show both products. The thermocycler was programmed with the following parameters: $45 \mathrm{~s}$ at $95^{\circ} \mathrm{C}, 45 \mathrm{~s}$ at $58^{\circ} \mathrm{C}, 75 \mathrm{~s}$ at $72^{\circ} \mathrm{C}$.

\section{RNA extraction, cDNA synthesis, RT-PCR, and quantitative RT-PCR.}

Total RNA was extracted from $100 \mathrm{mg}$ of ground rice root tissue using the PrepEase Plant RNA extraction kit according to the manufacturer's instructions (USB, Cleveland). Total RNA $(1 \mu \mathrm{g})$ was used as the template for first-strand cDNA synthesis using oligo dT primers (Invitrogen, La Jolla, CA, U.S.A.) and Superscript reverse transcriptase III (Invitrogen, La Jolla, CA, U.S.A.) following the manufacturer's instructions. The absence of contaminating genomic DNA was confirmed by performing a control PCR on RNA not reverse transcribed (-RT). RT-PCR was performed with $1 \mu \mathrm{l}$ of first-strand cDNA, using CYCLOPHILIN2 (The Institute for Genomic Research
[TIGR] identifier LOC_Os02g02890) and MtACTIN as internal standards in rice and $M$. truncatula, respectively.

For gene-expression studies in rice, primer sequences for realtime RT-PCR were adapted from Gutjahr and associates (2008). The primer sequences used to obtain amplicons were $5^{\prime}$-GTG AGGAAGGAGGTGGTGAA-3' and 5'-GTCGATGTCGAAG GTGGACT-3' for AMI (TIGR identifier LOC_Os04g04750); 5'-GTTACGTGGTGGTGGAGGAT-3' and 5'-GTCGAGGCAG ACCCACTG-3' for AM3 (TIGR identifier LOC_Os01g57400); 5'-ACTTCAGTTTCGTCGCGATT-3' and 5'-GGCAAAATCT GCTTCAATCC-3' for AM11 (TIGR identifier LOC_Os06g20120). The thermocycler was programmed with the following parameters: $30 \mathrm{~s}$ at $95^{\circ} \mathrm{C}, 45 \mathrm{~s}$ at $55^{\circ} \mathrm{C}$ (for $A M 1$ ) or at $57^{\circ} \mathrm{C}$ (for $A M 3$ and $A M 11$ ), $45 \mathrm{~s}$ at $72^{\circ} \mathrm{C}$.

For gene-expression studies in $M$. truncatula, primer sequences for quantitative real-time RT-PCR were adapted from Gleason and associates (2006). For ENOD11 expression experiments, $1-\mathrm{mm}$ root tips were excised at the time of harvest to minimize interference from nonsymbiotic ENOD11 expression. The primer sequences used to obtain amplicons were 5'-CTC

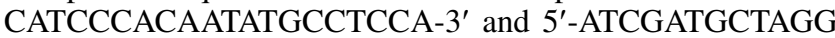
TGGAGGCT-3' for ENOD11; 5'-GCAGATGCTGAGGATATT AACCC-3' and 5'-CGACCACTTGCATAGAGGGAGAGG-3' for MtACTIN. Quantitative RT-PCR reactions were performed in triplicates on a MyiQ PCR machine (BioRad, Hercules, CA, U.S.A.), using SYBR Advantage qPCR premix (Clontech, Palo Alto, CA, U.S.A.). Cycling conditions were $95^{\circ} \mathrm{C}$ for $3 \mathrm{~min}$, followed by 40 cycles of $95^{\circ} \mathrm{C}$ for $10 \mathrm{~s}, 60^{\circ} \mathrm{C}$ for $20 \mathrm{~s}, 72^{\circ} \mathrm{C}$ for $45 \mathrm{~s}$, and $82^{\circ} \mathrm{C}$ for $10 \mathrm{~s}$. The specificity of the PCR amplification procedure was checked with a heat-dissociation step (from 55 to $95^{\circ} \mathrm{C}$ ) at the end of the run and by agarose gel electrophoresis. Results were standardized to MtACTIN expression levels and data was analyzed using the program GENEX (BioRad).

\section{ACKNOWLEDGMENTS}

The authors gratefully acknowledge the Department of Energy Great Lakes Bioenergy Research Center (DOE BER Office of Science DEFC02-07ER64494) at the University of Wisconsin, Madison for their financial support. We also thank J. Frugoli (Clemson University, Clemson, SC, U.S.A.) for critical comments and helpful suggestions and O. André for sending the primer sequences to genotype the pENOD11-gusA insertion.

\section{LITERATURE CITED}

Akiyama, K., and Hayashi, H. 2006. Strigolactones: Chemical signals in fungal symbionts and parasitic weeds in plant roots. Ann. Bot. 97:925931.

Akiyama, K., Matsuzaka, K., and Hayashi, H. 2005. Plant sesquiterpenes induce hyphal branching in arbuscular mycorrhizal fungi. Nature 435:750-751.

Amor, B. B., Shaw, S. L., Oldroyd, G. E. D., Maillet, F., Penmetsa, R. V., Cook, D., Long, S. R., Dénarié, J., and Gough, C. 2003. The NFP locus of Medicago truncatula controls an early step of Nod factor signal transduction upstream of a rapid calcium flux and root hair deformation. Plant J. 34:495-506.

Ané, J. M., Kiss, G. B., Riely, B. K., Penmetsa, R. V., Oldroyd, G. E., Ayax, C., Lévy, J., Debellé, F., Baek, J. M., Kaló, P., Rosenberg, C., Roe, B. A., Long, S. R., Dénarié, J., and Cook, D. R. 2004. Medicago truncatula DMII required for bacterial and fungal symbioses in legumes. Science 303:1364-1367.

Azcon-Aguilar, C., Rodriguez-Navarro, D., and Barea, J. 1981. Effects of ethrel on the formation and responses to VA mycorrhiza in Medicago and Triticum. Plant Soil 60:461-468.

Banba, M., Gutjahr, C., Miyao, A., Hirochika, H., Paszkowski, U., Kouchi, H., and Imaizumi-Anraku, H. 2008. Divergence of evolutionary ways among common sym genes: CASTOR and CCaMK show functional conservation between two symbiosis systems and constitute the root of a common signaling pathway. Plant Cell Physiol. 49:1659-1671.

Besserer, A., Puech-Pàges, V., Kiefer, P., Gomez-Roldan, V., Jauneau, A., Roy, S., Portais, J. C., Roux, C., Bécard, G., and Séjalon-Delmas, N. 
2006. Strigolactones stimulate arbuscular mycorrhizal fungi by activating mitochondria. PLoS Biol. 4:1239-1247.

Brundrett, M. C. 2002. Coevolution of roots and mycorrhizas of land plants. New Phytol. 154:275-304.

Brundrett, M. C. 2009. Mycorrhizal associations and other means of nutrition of vascular plants: Understanding the global diversity of host plants by resolving conflicting information and developing reliable means of diagnosis. Plant Soil 320:37-77.

Carpita, N. C., and McCann, M. C. 2008. Maize and sorghum: Genetic resources for bioenergy grasses. Trends Plant Sci. 13:415-420.

Catoira, R., Galera, C., de Billy, F., Penmetsa, R. V., Journet, E. P., Maillet, F., Rosenberg, C., Cook, D., Gough, C., and Dénarié, J. 2000. Four genes of Medicago truncatula controlling components of a Nod factor transduction pathway. Plant Cell 12:1647-1666.

Chabaud, M., Venard, C., Defaux-Petras, A., Bécard, G., and Barker, D. G. 2002. Targeted inoculation of Medicago truncatula in vitro root cultures reveals MtENOD11 expression during early stages of infection by arbuscular mycorrhizal fungi. New Phytol. 156:265-273.

Chen, C., Gao, M., Liu, J., and Zhu, H. 2007. Fungal symbiosis in rice requires an ortholog of a legume common symbiosis gene encoding a $\mathrm{Ca}^{2+} /$ calmodulin-dependent protein kinase. Plant Physiol. 145:16191628.

Chen, C., Ané, J. M., and Zhu, H. 2008. OsIPD3, an ortholog of the Medicago truncatula DMI3 interacting protein IPD3, is required for mycorrhizal symbiosis in rice. New Phytol. 180:311-315.

Chen, C., Fan, C., Gao, M., and Zhu, H. 2009. Antiquity and function of CASTOR and POLLUX, the twin ion channel-encoding genes key to the evolution of root symbioses in plants. Plant Physiol. 149:306-317.

Endre, G., Kereszt, A., Kevei, Z., Mihacea, S., Kaló, P., and Kiss, G. B. 2002. A receptor kinase gene regulating symbiotic nodule development. Nature 417:962-966.

Geil, R., and Guinel, F. 2002. Effects of elevated substrate-ethylene on colonization of leek (Allium porrum) by the arbuscular mycorrhizal fungi Glomus aggregatum. Can. J. Bot. 80:114-119.

Geil, R., Peterson, R., and Guinel, F. 2001. Morphological alterations of pea (Pisum sativum cv. Sparkle) arbuscular mycorrhizas as a result of exogenous ethylene treatment. Mycorrhiza 11:137-143.

Genre, A., Chabaud, M., Facio, A., Barker, D. G., and Bonfante, P. 2008. Prepenetration assembly precedes and predicts the colonization patterns of arbuscular mycorrhizal fungi within root cortex of both Medicago truncatula and Daucus carota. Plant Cell 20:1407-1420.

Gleason, C., Chaudhuri, S., Yang, T., Muñoz, A., Poovaiah, B. W., and Oldroyd, G. E. 2006. Nodulation independent of rhizobia induced by a calcium-activated kinase lacking autoinhibition. Nature 441:1149-1152.

Govindarajulu, M., Pfeffer, P. E., Jin, H. R., Abubaker, J., Douds, D. D., Allen, J. W., Bucking, H., Lammers, P. J., and Shachar-Hill, Y. 2005. Nitrogen transfer in the arbuscular mycorrhizal symbiosis. Nature 435:819-823

Groth, M., Takeda, N., Perry, J., Uchida, H., Draxl, S., Brachmann, A., Sato, S., Tabata, S., Kawaguchi, M., Wang, T. L., and Parniske, M. 2010. NENA, a Lotus japonicus homolog of Sec13, is required for rhizodermal infection by arbuscular mycorrhiza fungi and rhizobia but dispensable for cortical endosymbiotic development. Plant Cell 22:2509-2526.

Gutjahr, C., Banba, M., Croset, V., An, K., Miyao, A., An, G., Hirochika, H., Imaizumi-Anraku, H., and Paszkowski, U. 2008. Arbuscular mycorrhiza-specific signaling in rice transcends the common symbiosis signaling pathway. Plant Cell 20:2989-3005.

Gutjahr, C., Casieri, L., and Paszkowski, U. 2009. Glomus intraradices induces changes in root system architecture of rice independently of common symbiosis signaling. New Phytol. 182:829-837.

Harrison, M. J. 2005. Signaling in the arbuscular mycorrhizal symbiosis Annu. Rev. Microbiol. 59:19-42.

Harrison, M. J., Dewbre, G. R., and Liu, J. 2002. A phosphate transporter from Medicago truncatula involved in the acquisition of phosphate released by arbuscular mycorrhizal fungi. Plant Cell 14:2413-2429.

Hawkins, E. J., Johansen, A., and George, E. 2000. Uptake and transport of organic and inorganic nitrogen by arbuscular mycorrhizal fungi. Plant Soil 226:275-285.

Hochholdinger, F., and Zimmermann, R. 2008. Conserved and diverse mechanisms in root development. Curr. Opin. Plant Biol. 11:70-74.

Hochholdinger, F., Park, W. J., Sauer, M., and Woll, K. 2004. From weeds to crops: Genetic analysis of root development in cereals. Trends Plant Sci. 9:42-48.

Hodge, A., Campbell, C. D., and Fitter, A. H. 2001. An arbuscular mycorrhizal fungus accelerates decomposition and acquires nitrogen directly from organic material. Nature 413:297-299.

Imaizumi-Anraku, H., Takeda, N., Charpentier, M., Perry, J., Miwa, H., Umehara, Y., Kouchi, H., Murakami, Y., Mulder, L., Vickers, K., Pike, J., Downie, J. A., Wang, T., Sato, S., Asamizu, E., Tabata, S., Yoshikawa,
M., Murooka, Y., Wu, G. J., Kawaguchi, M., Kawasaki, S., Parniske, M., and Hayashi, M. 2005. Plastid proteins crucial for symbiotic fungal and bacterial entry into plant roots. Nature 433:527-531.

Javot, H., Penmetsa, R. V., Terzaghi, N., Cook, D. R., and Harrison, M. J. 2007. A Medicago truncatula phosphate transporter indispensable for the arbuscular mycorrhizal symbiosis. Proc. Natl. Acad. Sci. U.S.A. 104:1720-1725.

Journet, E. P., Pichon, M., Dedieu, A., de Billy, F., Truchet, G., and Barker, D. G. 1994. Rhizobium meliloti Nod factors elicit cell-specific transcription of the ENOD12 gene in transgenic alfalfa. Plant J. 6:241-249.

Journet, E. P., El-Gachtouli, N., Vernoud, V., de Billy, F., Pichon, M., Dedieu, A., Arnould, C., Morandi, D., Barker, D. G., and GianinazziPearson, V. 2001. Medicago truncatula ENOD11: A novel RPRP-encoding early nodulin gene expressed during mycorrhization in arbusculecontaining cells. Mol. Plant-Microbe Interact. 14:737-748.

Kanamori, N., Madsen, L. H., Radutoiu, S., Frantescu, M., Quistgaard, E. M. H., Miwa, H., Downie, J. A., James, E. K., Felle, H. H., Haaning, L. L., Jensen, T. H., Sato, S., Nakamura, Y., Tabata, S., Sandal, N., and Stougaard, J. 2006. A nucleoporin is required for induction of $\mathrm{Ca}^{2+}$ spiking in legume nodule development and essential for rhizobial and fungal symbiosis. Proc. Natl. Acad. Sci. U.S.A. 103:359-364.

Kieber, J. J., Rothenberg, M., Roman, G., Feldman, K. A., and Ecker, J. R. 1993. CTR1, a negative regulator of the ethylene response pathway in Arabidopsis, encodes a member of the Raf family of protein kinases. Cell 72:427-441.

Kistner, C., Winzer, T., Pitzschke, A., Mulder, L., Sato, S., Kaneko, T., Tabata, S., Sandal, N., Stougaard, J., Webb, K. J., Szczyglowski, K., and Parniske, M. 2005. Seven Lotus japonicus genes required for the transcriptional reprogramming of the root during fungal and bacterial symbiosis. Plant Cell 17:2217-2219.

Kosuta, S., Chabaud, M., Lougnon, G., Gough, C., Dénarié, J., Barker, D. G., and Bécard, G. 2003. A diffusible factor from arbuscular mycorrhizal fungi induces symbiosis-specific MtENOD11 expression in roots of Medicago truncatula. Plant Physiol. 131:952-962.

Kosuta, S., Hazledine, S., Sun, J., Miwa, H., Morris, R. J., Downie, J. A., and Oldroyd, G. E. D. 2008. Differential and chaotic calcium signatures in the symbiosis signaling pathway of legumes. Proc. Natl. Acad. Sci. U.S.A. 105:9823-9828.

Kuhn, H., Kuster, H., and Requena, N. 2010. Membrane steroid-binding protein 1 induced by a diffusible fungal signal is critical for mycorrhization in Medicago truncatula. New Phytol. 185:716-733.

Lévy, J., Bres, C., Geurts, R., Chalhoub, B., Kulikova, O., Duc, G., Journet, E. P., Ané, J. M., Lauber, E., Bisseling, T., Dénarié, J., Rosenberg, C., and Debellé, F. 2004. A putative $\mathrm{Ca}^{2+}$ and calmodulin-dependent protein kinase required for bacterial and fungal symbioses. Science 303:13611364

Liu, J., Blaylock, L., Endre, G., Cho, J., Town, C. D., VandenBosch, K. A., and Harrison, M. J. 2003. Transcript profiling coupled with spatial expression analyses reveals genes involved in distinct developmental stages of the arbuscular mycorrhizal symbiosis. Plant Cell 15:21062123

Messinese, E., Mun, J. H., Yeun, L. H., Jayaraman, D., Rouge, P., Barre, A., Lougnon, G., Schornack, S., Bono, J. J., Cook, D. R., and Ané, J. M. 2007. A novel nuclear protein interacts with the symbiotic DMI3 calcium- and calmodulin-dependent protein kinase of Medicago truncatula. Mol. Plant-Microbe Interact. 20:912-921.

Mitra, R. M., Gleason, C. A., Edwards, A., Hadfield, J., Downie, J. A Oldroyd, G. E., and Long, S. R. 2004a. A Ca ${ }^{2+} /$ calmodulin-dependent protein kinase required for symbiotic nodule development: Gene identification by transcript-based cloning. Proc. Natl. Acad. Sci. U.S.A. 101:4701-4705

Mitra, R. M., Shaw, S. L., and Long, S. R. 2004b. Six nonnodulating plan mutants defective for Nod factor-induced transcriptional changes associated with the legume-rhizobia symbiosis. Proc. Natl. Acad. Sci U.S.A. 101:10217-10222.

Monticelli, S., Puppi, G., and Damiano, C. 2000. Effects of in vivo mycorrhization on micropropagated fruit tree rootstocks. Appl. Soil Ecol. 15:105-111.

Mukherjee, A., and Ané, J. M. Plant hormones and initiation of legume nodulation and arbuscular mycorrhization. In: Environmental Aspects of Plant Nitrogen Metabolism. J. Polacco and C. Todd, eds. John Wiley \& Sons, Hoboken, NJ, U.S.A. In press

Navazio, L., Moscatiello, R., Genre, A., Novero, M., Baldan, B., Bonfante, P., and Mariani, P. 2007. A diffusible signal from arbuscular mycorrhizal fungi elicits a transient cytosolic calcium elevation in host plant cells. Plant Physiol. 144:673-681.

Negi, S., Ivanchenko, M. G., and Muday, G. 2008. Ethylene regulates lateral root formation and auxin transport in Arabidopsis thaliana. Plant $\mathrm{J}$. 55:175-187.

Negi, S., Sukumar, P., Liu, X., Cohen, J. D., and Muday, G. K. 2010. Ge- 
netic dissection of the role of ethylene in regulating auxin-dependent lateral and adventitious root formation in tomato. Plant J. 61:3-15.

Nukui, N., Ezura, H., and Minamisawa, K. 2004. Transgenic Lotus japonicus with an ethylene receptor gene $\mathrm{Cm}-\mathrm{ERS1/H70A}$ enhances formation of infection threads and nodule primordia. Plant Cell Physiol. 45:427435

Oláh, B., Brière, C., Bécard, G., Dénarié, J., and Gough, C. 2005. Nod factors and a diffusible factor from arbuscular mycorrhizal fungi stimulate lateral root formation in Medicago truncatula via the DMII/DMI2 signaling pathway. Plant J. 44:195-207.

Oldroyd, G. E. D., Engstrom, E. M., and Long, S. R. 2001. Ethylene inhibits the Nod factor signal trasnduction pathway of Medicago truncatula. Plant Cell 13:1835-1849.

Paszkowski, U., and Boller, T. 2002. The growth defect of lrt1, a maize mutant lacking lateral roots, can be complemented by symbiotic fungi or high phosphate nutrition. Planta 214:584-590.

Peiter, E., Sun, J., Heckmann, A. B., Venkateshwaran, M., Riely, B. K., Otegui, M. S., Edwards, A., Freshour, G., Hahn, M. G., Cook, D. R., Sanders, D., Oldroyd, G. E., Downie, J. A., and Ané, J. M. 2007. The Medicago truncatula DMI1 protein modulates cytosolic calcium signaling. Plant Physiol. 145:192-203.

Penmetsa, R. V., and Cook, D. 1997. A legume ethylene-insensitive mutan hyperinfected by its rhizobial symbiont. Science 275:527-530.

Penmetsa, R. V., Uribe, P., Anderson, J., Lichtenzveig, J., Gish, J. C., Nam, Y. W., Engstrom, E., Xu, K., Sckisel, G., Pereira, M., Baek, J. M., Lopez-Meyer, M., Long, S. R., Harrison, M. J., Singh, K. B., Kiss, G. B., and Cook, D. R. 2008. The Medicago truncatula ortholog of Arabidopsis EIN2, sickle, is a negative regulator of symbiotic and pathogenic microbial associations. Plant J. 55:580-595.

Peters, N. K., Frost, J. W., and Long, S. R. 1986. A plant flavone, luteolin, induces expression of Rhizobium meliloti nodulation genes. Science 233:977-980.

Pirozynski, K. A., and Malloch, D. W. 1975. Origin of land plants - matter of mycotrophism. Biosystems 6:153-164.

Price, N. S., Roncadori, R. W., and Hussey, R. S. 1989. Cotton root growth as influenced by phosphorus nutrition and vesicular-arbuscular mycorrhizas. New Phytol. 111:61-66.

Read, D. J., Duckett, J. G., Francis, R., Ligrone, R., and Russell, A. 2000. Symbiotic fungal associations in 'lower' land plants. Philos. Trans. R. Soc. Lond. B Biol. Sci. 355:815-830.

Rebouillat, J., Dievart, A., Verdeil, J., Escoute, J., Giese, G., Breitler, J., Gantet, P., Espeout, S., Guideroni, E., and Perin, C. 2008. Molecular genetics of rice root development. Rice 2:15-34.

Riely, B. K., Lougnon, G., Ané, J. M., and Cook, D. R. 2007. The symbiotic ion channel homolog DMI1 is localized in the nuclear membrane of Medicago truncatula roots. Plant J. 49:208-216.

Rolfe, B. J. 1988. Flavones and isoflavones as inducing substances of legume nodulation. Biofactors 1:3-10.
Saito, K., Yoshikawa, M., Yano, K., Miwa, H., Uchida, H., Asamizu, E., Sato, S., Tabata, S., Imaizumi-Anraku, H., Umehara, Y., Kouchi, H., Murooka, Y., Szczyglowski, K., Downie, J. A., Parniske, M., Hayashi, M., and Kawaguchi, M. 2007. NUCLEOPORIN85 is required for calcium spiking, fungal and bacterial symbioses, and seed production in Lotus japonicus. Plant Cell 19:610-624.

Siciliano, V., Genre, A., Balestrini, R., Cappellazzo, G., deWitt, P. J. G. M., and Bonfante, P. 2007. Transcriptome analysis of arbuscular mycorrhizal roots during development of the pre-penetration apparatus. Plant Physiol. 144:1455-1466.

Simon, L., Bousquet, J., Lévesque, R. C., and Lalonde, M. 1993. Origin and diversification of endomycorrhizal fungi and coincidence with vascular land plants. Nature 363:67-69.

Smit, P., Raedts, J., Portyanko, V., Debellé, F., Gough, C., Bisseling, T., and Geurts, R. 2005. NSP1 of the GRAS protein family is essential for rhizobial Nod factor-induced transcription. Science 308:1789-1791.

Smith, S. E., and Gianinazzi-Pearson, V. 1988. Physiological interactions between symbionts invesicular-arbuscular mycorrhizal plants. Annu. Rev. Plant Physiol. Plant Mol. Biol. 39:221-244.

Stougaard, J. 2000. Regulators and regulation of legume root nodule development. Plant Physiol. 124:531-540.

Stracke, S., Kistner, C., Yoshida, S., Mulder, L., Sato, S., Kaneko, T., Tabata, S., Sandal, N., Stougaard, J., Szczyglowski, K., and Parniske, M. 2002. A plant receptor-like kinase required for both bacterial and fungal symbiosis. Nature 417:959-962.

Subramanian, K. S., Tenshia, V., Jayalakshmi, K., and Ramachandran, V. 2009. Role of arbuscular mycorrhizal fungus (Glomus intraradices)(fungus aided) in zinc nutrition of maize. J. Agric. Biotechnol. Sustain Dev. 1:29-38.

Szczyglowski, K., Shaw, R. S., Woperis, J., Copeland, S., Hamburger, D., Kasiborski, B., Dazzo, F. B., and de Bruijn, F. J. 1998. Nodule organogenesis and symbiotic mutants of the model legume Lotus japonicus. Mol. Plant-Microbe Interact. 11:684-697.

Wang, B., and Qiu, Y. L. 2006. Phylogenetic distribution and evolution of mycorrhizas in land plants. Mycorrhiza 16:299-363.

Wang, B., Yeun, L. H., Xue, J., Liu, Y., Ané, J. M., and Qiu, Y. L. 2010. Presence of three mycorrhizal genes in the common ancestor of land plants suggests a key role of mycorrhizas in the colonization of land by plants. New Phytol. 186:514-525.

Yano, K., Yamauchi, A., and Kono, Y. 1996. Localized alteration in lateral root development in roots colonized by an arbuscular mycorrhizal fungus. Mycorrhiza 6:409-415.

Yano, K., Yoshida, S., Muller, J., Singh, S., Banba, M., Vickers, K. Markmann, K., White, C., Schuller, B., Sato, S., Asamizu, E., Tabata, S., Murooka, Y., Perry, J., Wang, T., Kawagachi, M., Imaizumi-Anraku, H., Hayashi, M., and Parniske, M. 2008. CYCLOPS, a mediator of symbiotic intracellular accommodation. Proc. Natl. Acad. Sci. U.S.A. 105:20540-20545. 